\title{
Spinal Infections: An Update
}

\author{
Andreas G. Tsantes ${ }^{1,2}$, Dimitrios V. Papadopoulos ${ }^{1}$, Georgia Vrioni ${ }^{2}$, Spyridon Sioutis ${ }^{1}$, \\ George Sapkas ${ }^{1}$, Ahmed Benzakour ${ }^{3}$, Thami Benzakour ${ }^{4}$, Andrea Angelini ${ }^{5}{ }^{(0)}$, \\ Pietro Ruggieri ${ }^{5}[$ and Andreas F. Mavrogenis $1, * \mathbb{C}$ on behalf of the World Association against \\ Infection in Orthopedics and Trauma (W.A.I.O.T.) Study Group on Bone and Joint \\ Infection Definitions
}

1 First Department of Orthopaedics, National and Kapodistrian University of Athens, School of Medicine, 11527 Athens, Greece; andreas.tsantes@yahoo.com (A.G.T.); d.papado@yahoo.gr (D.V.P.); sp.sioutis@gmail.com (S.S.); gsapkas1@gmail.com (G.S.)

2 Department of Microbiology, National and Kapodistrian University of Athens, School of Medicine, 11527 Athens, Greece; gvrioni@med.uoa.gr

3 Spinal Surgery Office, Clinique de 1' Archette, 45160 Olivet, France; benzak@hotmail.fr

4 Zerktouni Orthopaedic Clinic, 20000 Casablanca, Morocco; t.benzakour@gmail.com

5 Department of Orthopaedics and Orthopaedic Oncology, University of Padova, 35128 Padua, Italy; andrea.angelini83@yahoo.it (A.A.); pietro.ruggieri@unipd.it (P.R.)

* Correspondence: afm@otenet.gr

Received: 3 March 2020; Accepted: 23 March 2020; Published: 27 March 2020 updates

\begin{abstract}
Spinal infection poses a demanding diagnostic and treatment problem for which a multidisciplinary approach with spine surgeons, radiologists, and infectious disease specialists is required. Infections are usually caused by bacterial microorganisms, although fungal infections can also occur. The most common route for spinal infection is through hematogenous spread of the microorganism from a distant infected area. Most patients with spinal infections diagnosed in early stages can be successfully managed conservatively with antibiotics, bed rest, and spinal braces. In cases of gross or pending instability, progressive neurological deficits, failure of conservative treatment, spinal abscess formation, severe symptoms indicating sepsis, and failure of previous conservative treatment, surgical treatment is required. In either case, close monitoring of the patients with spinal infection with serial neurological examinations and imaging studies is necessary.
\end{abstract}

Keywords: spine; abscess; spondylitis; spondylodiscitis; instrumentation

\section{Introduction}

Spinal infections constitute a demanding diagnostic and treatment problem that in most cases necessitates a multidisciplinary approach with spine surgeons, radiologists, and infectious disease specialists. Infections are usually caused by bacterial microorganisms, although fungal infections can also occur. The nomenclature for spinal infections is complex and confusing since under the umbrella term "spinal infections" a heterogeneous group of infections is included (Table 1). This nomenclature correlates with several different aspects of the infection such as the causative pathogen, the underlying pathophysiology, or the involved part of the spinal column [1].

On the basis of the pathogen, bacterial spinal infections can be either pyogenic or granulomatous such as tuberculosis or brucellosis; any part of the spinal column can be affected correlating to different terms such as spondylodiscitis or discitis [1]. The infection can also spread inside the spinal canal, involving the dural sac or the epidural space, or to the paravertebral soft tissue. However, in most cases, the infection is not confined to only one anatomical compartment, it usually spreads and involves several different elements of the spinal column [2]. 
Table 1. Terminology of the spinal infections.

\begin{tabular}{ccc}
\hline Term & Site of Infection & Features \\
\hline Discitis & Intervertebral disc & Common in children \\
\hline Spondylitis & $\begin{array}{c}\text { Vertebral end plate and } \\
\text { vertebral body }\end{array}$ & $\begin{array}{c}\text { Similar to osteomyelitis, usually seen at early } \\
\text { stage of infection in adults }\end{array}$ \\
\hline Spondylodiscitis & Disc and adjacent vertebral body & Most common form of spinal infection \\
\hline Septic facet joint & Facet joints & $\begin{array}{c}\text { Hematogenous spread to the facet joints, } \\
\text { increasingly diagnosed over the past years }\end{array}$ \\
\hline Epidural abscess & Epidural space & $\begin{array}{c}\text { Rarely seen as isolated abscess, contiguous } \\
\text { spread of infection into the medullary canal }\end{array}$ \\
\hline
\end{tabular}

Spinal infections can also be classified based on the pathophysiology of the infection, and specifically based on the route of spread of the responsible pathogen [1]. Usually, infections originate from a distant site and via hematogenous spread, the microorganism reaches the spine. In other cases, the spinal column is infected through continuous spread from an adjacent infection. Last, infections can develop due to direct inoculation of the culprit microorganism during surgery or following local trauma (surgery or injury). The risk for postoperative infection following spinal surgery varies because it depends on many factors, importantly the type of the spinal procedure; the overall incidence of postoperative spinal infection is estimated from $0 \%$ to $18 \%$ [3]. In the last scenario the infection is also called secondary, as opposed to primary spinal infection that occurs without any previous history of trauma [3]. This article aims to summarize and critically examine the current evidence for spinal infections in a comprehensive review that the curious reader may find interesting and educative.

\section{Epidemiology}

The overall incidence of spinal infections is approximately 2.2/100,000 per year [4,5]. The most common type of spinal infection is primary pyogenic spondylodiscitis, in which a bacterial microorganism infects the vertebral body and the intervertebral disc via hematogenous spread [6]. For reasons that are not fully elucidated, spondylodiscitis is twice as common in men [7]. Although spinal infections can affect patients of any age starting from infancy, vertebral spondylodiscitis most commonly occurs in adults and has a predilection for patients aged $>50$ years; intravenous drug abusers are a younger age group with high susceptibility to spinal infections [8,9]. There are several factors that can possibly explain the higher prevalence of spinal infections in older people including immunosuppressive medications, intravascular devices, and other forms of implants that are more common in older patients [10].

The most frequently involved spinal segment is the lumbar spine (58\%), followed by the thoracic spine (30\%), and the cervical spine (11\%) [6]. Hematogenous sacral infection is rare [11-13]. In most cases, sacral osteomyelitis results from pressure ulcers, trauma, surgery, or through contiguous spread from a pelvic infection [11,12]. The spinal infection can extend posteriorly and result in epidural or subdural abscess, or even meningitis, while lateral spread can result in psoas, retroperitoneal, subphrenic, paravertebral, retropharyngeal, and mediastinal abscesses. The most common culprit for epidural or psoas muscle abscesses is Gram-positive bacteria [13]. Other parts of the vertebrae that can be infected include the facet joints and the spinous processes [14].

As with any infection, any disease that compromises the immune system such as diabetes mellitus, HIV/AIDS infection, malignancy, renal failure, hepatic cirrhosis, and malnutrition poses a significant risk factor for a patient to experience a spinal infection [15-21]. Medications such as immunosuppressive agents following organ transplantation or long-term corticosteroids also increase the risk for spinal infections. Other significant risk factors for spinal infections include previous spinal surgery and presence of intravascular or orthopaedic implants. Last, intravenous drug abusers are 
susceptible to infections not only because of their deteriorated immunologic defense, but also because of the high risk for injection site infections from infected needles or vasculitis [4].

\section{Pathogenesis}

Bacteria can reach the spine and infect the spinal column via the following three routes: (1) hematogenous spread from a remote site, (2) direct external inoculation after trauma (injury or surgery), and (3) dissemination from a contiguous tissue [1]. Hematogenous spread is the most common route for vertebral osteomyelitis in children and adults [22-29]. Generally, any condition that results in circulation of microorganisms into the blood stream (bacteremia) such as surgery or more benign events such as tooth brushing or venipuncture, can lead to hematogenous spondylodiscitis. Infection in the urinary tract, often following genitourinary procedures, is the most common source of transient bacteremia and subsequent spinal infection [22-29]. Other common potential primary sources for hematogenous spondylodiscitis include gastrointestinal infections, otitis media, oral cavity infections, infective endocarditis, skin and soft tissue infections, respiratory tract infections, and infected intravenous catheter sites. In almost 50\% of cases, the primary source of infection is not identifiable [30]. Secondary spinal infections due to direct inoculation can occur after spinal surgery or minimally invasive spinal procedures such as chemonucleolysis or discography, or after penetrating trauma in the spinal area [31-38]. Contiguous spread to the spine from an infection in an adjacent structure such as the aorta, the esophagus, or the bowel have been also reported $[39,40]$.

Considering the vasculature of the spine, the same vascular pedicle bifurcates supply two adjacent vertebral end plates; therefore, in most cases infection involves two adjacent vertebral bodies and their intermediate disc [1]. The vertebral end plates are the first to be infected, and at a subsequent time the infection propagates to the adjacent disc or to the vertebral body. Furthermore, the slow blood flow in these vessels, the lack of valves, and convolution of the arterial or venous supply make vertebral column more susceptible to develop an infection in patients with bacteremia [1]. In children, as opposed to adults, the infection can spread more easily since the blood vessels in the end plates extend to supply the intervertebral discs as well [41].

\section{Clinical Presentation}

The most common complaints of patients with spinal infection is back or neck pain, depending on the location of the infection. Occasionally, pain radiates to the lower limbs, genital area, groin, or even to the abdomen. Pain usually aggravates at night and can be severe enough to awaken the patient. Although it is very difficult to differentiate the common mechanical back pain from a spinal infection, spondylodiscitis should always be investigated in febrile patients with back pain [1]. However, although fever is a common symptom, it is not always present; approximately $50 \%$ of the patients with pyogenic spine infections, and even in a higher percentage of patients with fungal, mycobacterial, and brucellar infections are afebrile [3].

On physical examination, inspection should assess for any scar indicating a previous surgery or trauma. In addition, any deformity such as kyphosis or scoliosis should be noted. On palpation, paravertebral muscle spasm can be felt, while marked tenderness with percussion over spinous processes of the infected spinal segment is a more consistent finding, reported to be present in $75 \%$ to $95 \%$ of the cases. However, rarely, in patients with Charcot arthropathy and paraplegics is pain minimal or absent [1]. Approximately 30\% of the patients present with neurological symptoms including paresthesia and muscle weakness [5]. In the case of epidural abscesses resulting from posterior extension of the infection to the epidural space, neurological deficits including radiculopathy, weakness or paralysis, and paresthesia is more common (Figure 1) [42]. Due to the low specificity of symptoms and signs, diagnosis can be delayed for several weeks or even months; therefore, increased awareness and clinical suspicion is necessary. 

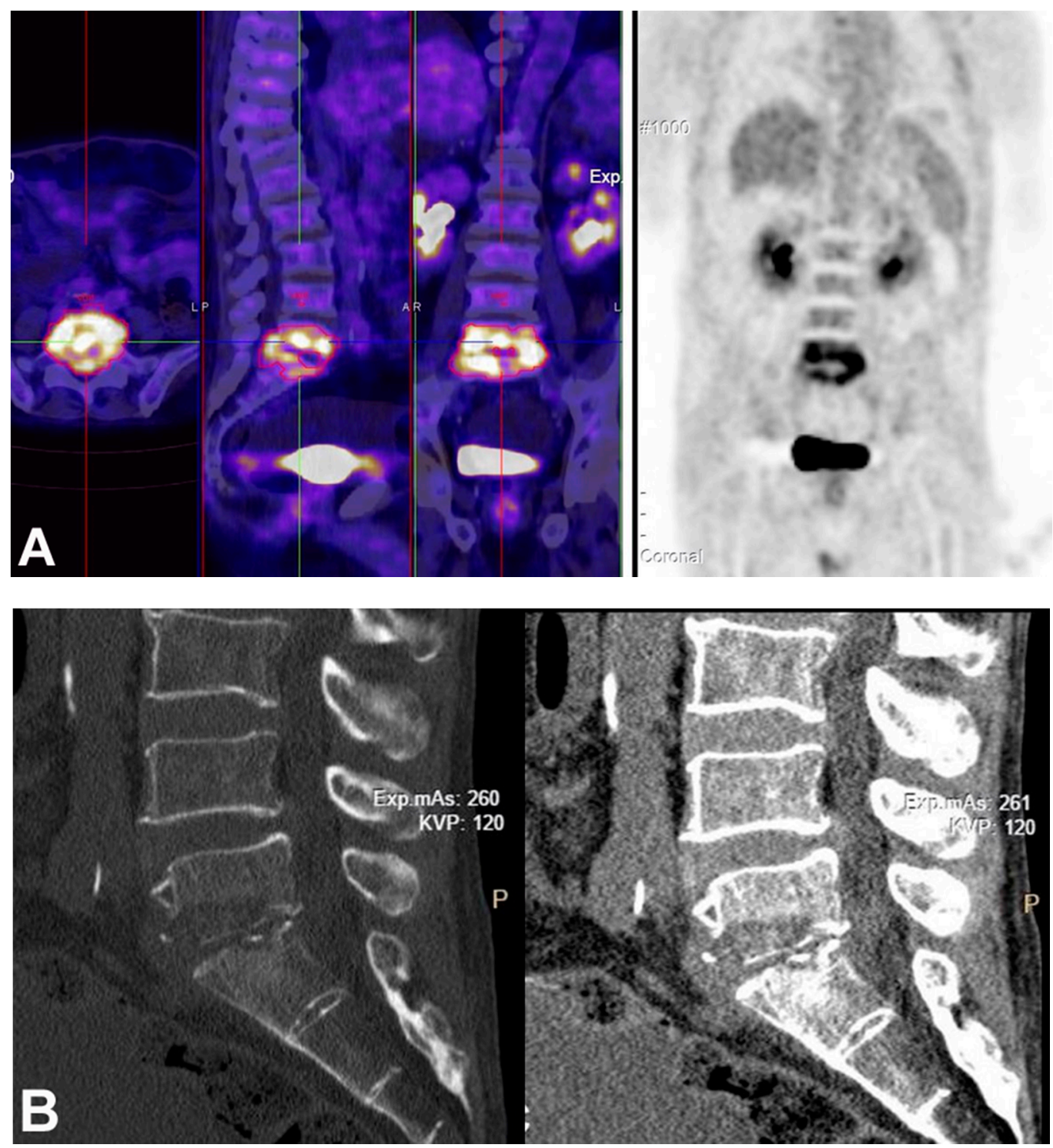

Figure 1. Cont. 


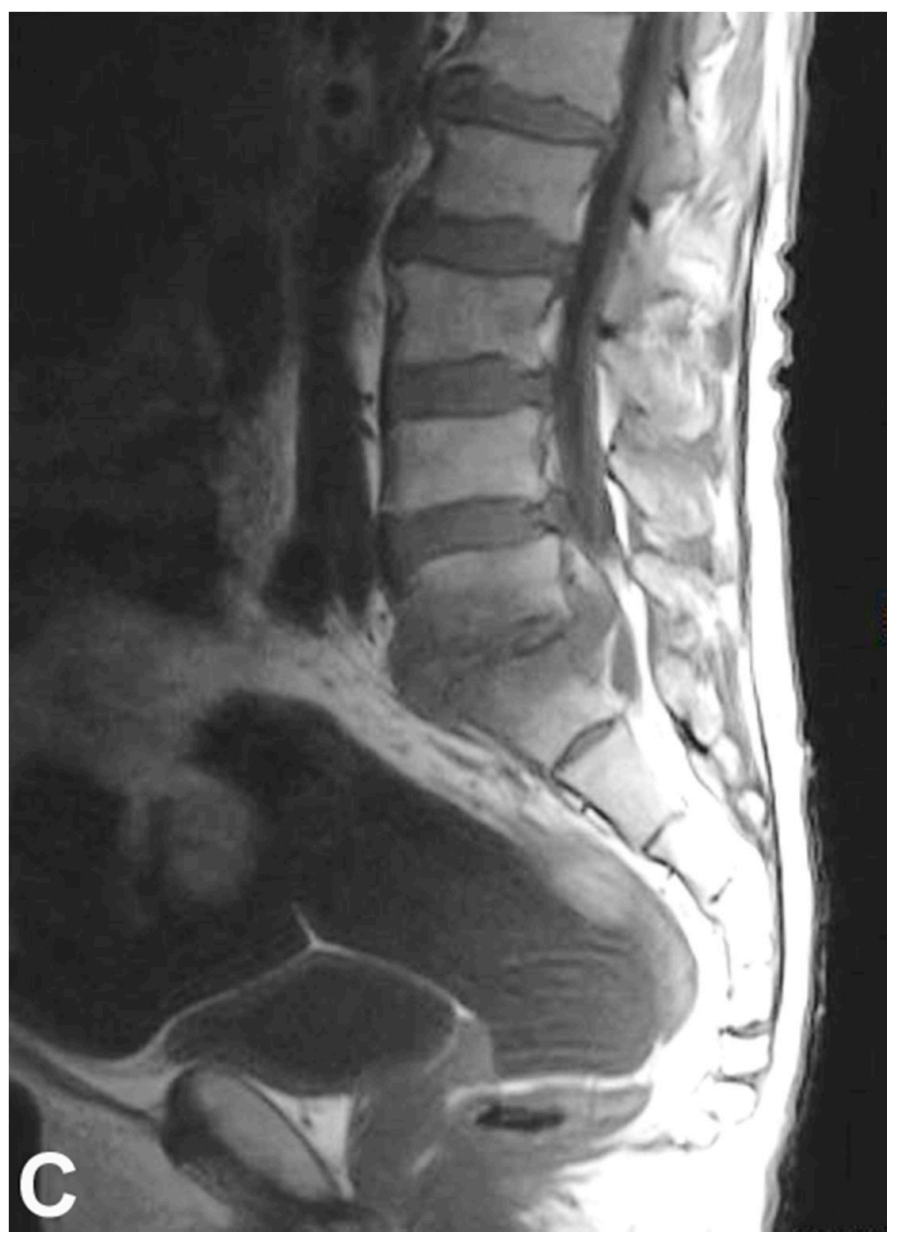

Figure 1. A 64-year-old man with HBV-related hepatic cirrhosis, and L5-S1 MRSA spondylodiscitis. (A) PET/CT shows diffuse uptake at the L5-S1 level (SUV, 4.06); (B) Sagittal CT scans show complete destruction of the L5-S1 intervertebral disc and erosion of L5 and S1 vertebra; (C) T1-weighted magnetic resonance (MR) imaging shows abscess formation at the L5-S1 level. He was treated with antibiotics and surgical decompression.

\section{Diagnosis}

The diagnostic approach (Figure 2) for the patients with spinal infections should begin with a complete medical history and physical examination during which possible risk factors for infection must be always investigated and identified. Initial blood work-up should include white blood cell count (WBC) and inflammatory markers such as erythrocyte sedimentation rate (ESR) and C-reactive protein (CRP). CRP is considered to have the highest sensitivity as compared with other blood tests (98\%), while elevated ESR is observed in $75 \%$ of cases $[1,21,27]$. However, a sole elevation of CRP can be misleading, thus, an elevated CRP in conjunction with elevated ESR or WBC and clinical symptoms consistent with spinal infection (such as back pain and fever) are more indicative of a spinal infection. CRP is also a useful marker of response to antimicrobial therapy because it normalizes rapidly after successful treatment, as opposed to ESR that can remain elevated for a long time after clinical improvement [1]. WBC is a less useful laboratory parameter as compared with CRP and ESR, because it is normal in up to $55 \%$ of patients with spinal infections [21]. Brucella serology is mandatory in cases with signs and symptoms indicating brucellosis, exposure to a potential source, or in endemic areas [27]. Interferon-gamma (IFN- $\gamma$ ) release assay should be also performed in patients with risk factors for tuberculosis such as immigrants, low socioeconomical status, and endemic countries. This assay can be also useful for exclusion of active spinal tuberculosis, due to its high (95\%) negative predictive value [43]. 


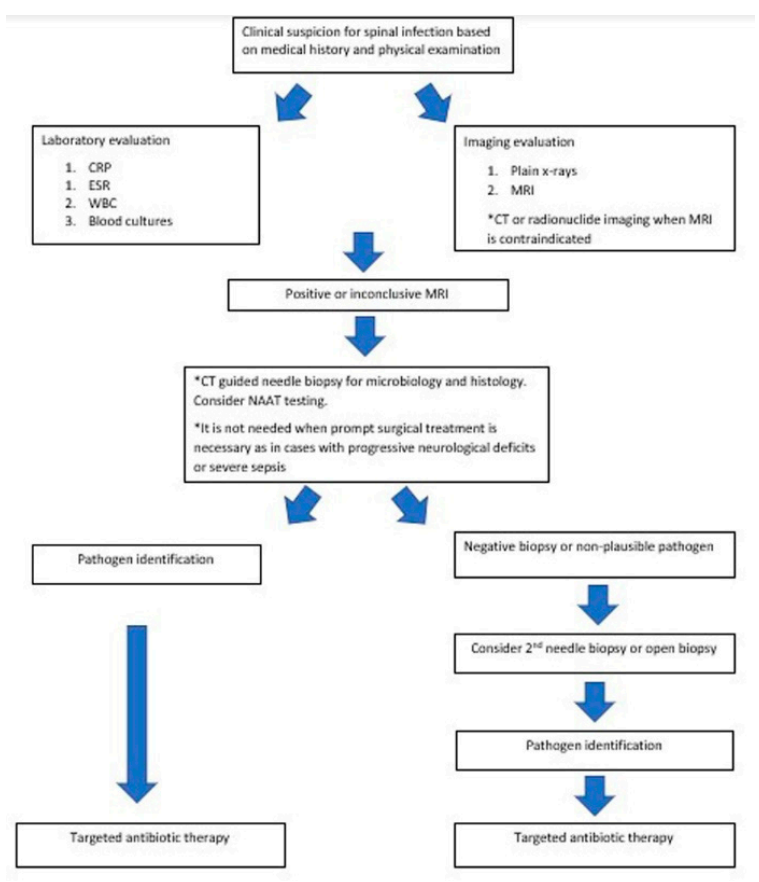

Figure 2. Diagnostic algorithm for spinal infections.

Imaging evaluation of the patients with spinal infections should include radiographs of the spine and magnetic resonance (MR) imaging with contrast medium administration [44]. Typical MR imaging findings of spondylodiscitis include (1) hypointense vertebral bodies and disc with loss of endplate definition in T1-weighted images, (2) hyperintense vertebral bodies and disc with loss of endplate definition in T2-weighted images or STIR images, and (3) contrast enhancement of the vertebral body and disc. Imaging should include the entire spine in order to assess the extension of the infection and to exclude any adjacent or skip lesions. Bone scintigraphy with technetium or labelled leucocytes is not routinely indicated because of their low sensitivity and specificity; gallium scans can have a role because if the result is negative, osteomyelitis is unlikely [45]. Newer tracers for bone scintigraphy such as indium-111 labeled (111In) biotin and streptavidin have been recently introduced [46]. Streptavidin accumulates in sites of inflammation and infection, while 111In-biotin has a high affinity for streptavidin; a sensitivity, specificity and diagnostic accuracy of $94 \%, 95 \%$, and $94 \%$, respectively has been reported with the Streptavidin/111In-biotin scan for spinal infections [46]. Other new tracers include the technetium Tc-99m-ubiquicidin-derived peptide that has a high affinity to sites with viable bacterial growth, in addition to radiolabeled antifungal tracers for differentiation of fungal from bacterial infections [47]. At present, the Current Infectious Diseases Society of America (IDSA) guidelines recommend the use of 18F-FDG-PET/CT only in cases that MR imaging is contraindicated [27].

Although with a relatively low sensitivity, at least two sets of blood cultures for aerobic and anaerobic bacteria should be obtained [2]; in approximately $60 \%$ of spinal infections, the implicated pathogen can be identified in blood cultures [1]. Cultures on specific media for Mycobacterium tuberculosis and fungi should be requested as well, especially when there is a suspicion for tuberculosis exposure or indicating imaging signs [7]. A CT-guided percutaneous needle aspiration biopsy is paramount to confirm the diagnosis and isolate the responsible microorganism, provided that prompt surgical treatment is not required such as in cases with progressive neurological symptoms due to spinal cord compression or spinal canal abscesses [48]. However, the sensitivity and specificity of CT-guided needle biopsy is lower than believed; in a recent metanalysis, a sensitivity of $52.2 \%$ (95\% CI, 45.8-58.5) for CT-guided percutaneous needle aspiration biopsy for the diagnosis of spinal infections was reported [48]. Recent studies reported a higher pathogen detection rate of fine-needle aspiration with combined superimposed MR and CT imaging [49,50]. Aspirate of the disc or paraspinal soft tissue lesions should be obtained, and samples should be sent for microbiology, histology, and ideally 
for nucleic acid amplification testing (NAAT). Kim et al. showed that the pathogen detection rate of soft tissue sampling is 2.28 times higher as compared with bone tissue [51]. NAAT such as polymerase chain reaction (PCR) testing is useful in cases of negative aerobic and anaerobic cultures in patients who have already taken antibiotics. NAAT testing is also useful in cases of unusual microorganisms or slow growing bacteria such as Mycobacterium tuberculosis or Coxiella burnetii [52,53]. Histopathology is useful, especially when cultures are negative. The presence of leucocytes in histological sections indicates bacterial infection, while granuloma formations indicates specific pathogens such as Mycobacterium Tuberculosis or Brucella. When clinical symptoms and imaging are typical for vertebral osteomyelitis, and blood cultures are positive for a common pathogen such as Staphylococcus aureus, a needle biopsy is not required [11].

Although it is a common practice to withhold antibiotics prior to biopsy, recent studies have shown that antibiotics prior to biopsy do not result in lower culture sensitivity [54,55]. Additionally, in cases of critically ill patients such as in septicemia, empirical antibiotic therapy should start promptly without any delay [27]. In cases of negative blood cultures with two consecutive negative needle biopsies, open biopsy is recommended. Open biopsy for tissue sampling yields a pathogen detection rate of $68 \%$ to $93 \%$ [56].

\section{Differential Diagnosis}

In some cases, symptoms of spinal infections can be very similar to those of other spinal pathologies, and thus differential diagnosis is warranted. Especially in elderly patients with no fever, misdiagnosis is very common. Spinal infections should be differentiated from spinal tumors, spinal stenosis, herniated nucleus pulposus, and simple muscle strains. MR imaging is very useful in differentiating spinal stenosis and herniated nucleus pulposus from infection since the imaging findings are unique for each pathology. Apart from imaging studies, clinical evaluation can be also helpful to differentiate mechanical pain (with or without neurological symptoms) from infections. There are some distinctive features between the typical mechanical back pain and the pain due to a spinal infection; in patients with mechanical back pain due to muscle sprain, pain aggravates with upright posture and with daily activities; in contrast, in patients with spinal infections the pain is constant regardless of the activity and can aggravate at rest and night [1]. Differential diagnosis between spinal tumors and infections is more difficult and complicated. Frequently, the clinical manifestation, MR imaging findings, and laboratory tests are inconclusive. In these cases, biopsy is required as it is the only reliable method to distinguish these two conditions.

\section{Microbiology}

Although there is a wide range of bacteria that can cause spinal infections, in most cases these infections are caused by a single microorganism rather than from multiple pathogens [45]. In those few poly-microbial infections ( $<10 \%$ of cases), the spine is usually affected through contiguous spread [30]. In hematogenous spinal infections, in almost 50\% of the cases, the source of infection can be identified [30]; this is most commonly the genitourinary tract (17\%) followed by endocarditis (12\%), skin and soft tissue (11\%), gastrointestinal (5\%), and respiratory system (2\%) [57].

In general, three major groups of microorganisms cause spinal infections, i.e., bacteria (pyogenic infections), fungi, and very rarely parasites. In the past, Mycobacterium tuberculosis was considered to be the most common cause for spinal infections, with some studies reporting tuberculosis in $50 \%$ of the patients with spinal infections [28]. In recent times, however, the microbiology of spinal infections has changed; currently, most spinal infections are pyogenic, with Mycobacterium tuberculosis being the isolate in $<25 \%$ of the cases in certain areas [57]. Among all pathogens, Staphylococcus aureus is the most common microorganism, responsible for $20 \%$ to $84 \%$ of all spinal infections, while approximately $5 \%$ to $20 \%$ of spinal infections are caused by Streptococci and Enterococci, and in $<4 \%$ of the cases by anaerobic microorganisms [58-60]. Enterobacteriae spp. are considered to be the culprit in $7 \%$ to $33 \%$ of pyogenic infections, with Escherichia coli being the most common microorganism of this group, followed by 
Proteus and Klebsiella. The latter microorganisms are common causes of urinary tract or gastrointestinal infections, especially in diabetic or immunosuppressed patients [16,61]. Salmonellosis, caused by a pathogen of the same species, is frequently seen in children with sickle-cell disease [62]. Vertebral osteomyelitis caused by Pseudomonas aeruginosa is common in intravenous drug users, although Staphylococcus aureus remains the most common microorganism in this group of patients as well $[63,64]$. In patients with implants, such as patients with prosthetic joint replacements, the risk of Staphylococcus epidermidis spinal infection is higher [61]. Other coagulase-negative Staphylococci such as Staphylococcus viridans can cause low-grade infections due to their lower virulence. Fungal infections are very rare, and most commonly affect immunocompromised patients [1]. Another microorganism that has been implicated in orthopedic infections is Cutibacterium Acnes, formerly known as Propionibacterium Acnes. Cutibacterium acnes is a Gram-positive anaerobic-aerotolerant bacillus and is part of the normal human flora as it resides in skin follicles, in the eye mucosa, and in the oral cavity or in the rest of the gastrointestinal tract. The percentage of bone infections caused by Cutibacterium acnes varies, ranging from $2 \%$ to $18 \%$ [2]. Its association with orthopaedic infections is not entirely clear. The reasons for that are that in the past it was considered to be a culture contaminant due its normal presence in the skin, while the infection from this pathogen is in many cases subclinical and delayed. On the one hand, there are increasing data, especially in shoulder surgeries, that point towards its causative role in postoperative infections. On the other hand, there are only few data regarding Cutibacterium acnes in spinal infections. Interestingly, there are studies reporting positive cultures for Cutibacterium acnes in disc material of herniated discs, implicating this microorganism in the development of disc herniation [2]. There are slight differences regarding the microbiology of spinal infections in children; in this age group, Staphylococcus aureus and Streptococcus spp. are the most common pathogens, while another common isolate for spondylodiscitis or discitis in children is Kingella kingae [65]. The reason for the more frequent report of Kingella kingae as an etiologic factor for osteoarticular infections in children is because now this pathogen can be more easily detected. Although this Gram-negative organism is difficult to be isolated in several body fluids, the use of aerobic blood culture vials or NAAT testing such as PCR, lead to identification of this bacterium as a cause of many infections in ages 6 months to 4 years, a group in whom traditional culture is very frequently negative.

Pathogens for spinal infections also vary depending on geographic location. The incidence of infection from Brucella is considerably higher in Mediterranean and Middle Eastern countries, with the spine involved in $6 \%$ to $12 \%$ of patients with brucellosis [66]. Similarly, although spinal infections from Echinococcus are extremely rare, they can be seen occasionally in endemic regions such as countries with a warm climate such as South America, central Asia, China, Australia, and Africa [67].

\section{Conservative Treatment Antibiotics}

The goals of conservative treatment for patients with spinal infections is eradication of the infection and pain relief, while spinal stability is preserved, and neurological dysfunction is prevented. In approximately $90 \%$ of the cases, conservative treatment is successful in achieving these goals [68]. Conservative treatment includes appropriate antibiotic therapy and pain medications combined with spinal brace immobilization and physical therapy. Bed rest is usually recommended, especially during the initial period in the context of pain relief and prevention of spinal deformity. Usually, this period should last approximately one to two weeks, or until pain improvement. Following this period, ambulation with a spinal brace is recommended. In rare cases, where the infection has significantly spread and affected a major part of the anterior spinal column, a longer period of bed rest, up to six weeks, could be necessary [1]. However, a long immobilization period is associated with increased morbidity, especially in elderly patients, in whom the risk for certain complications such as pressure ulcers, pulmonary embolism, or respiratory tract infections is high [3]. In cases of cervical spine infections, immobilization can be obtained with a neck collar or with a halo-vest in more advanced cases with extensive bone destruction. In the thoracic spine, an extension brace that can prevent a kyphotic deformity of the spine is recommended. Accordingly, a lower thoracolumbar or lumbosacral brace is indicated when the thoracolumbar or the lumbar spine are involved [1]. 
Despite the high rate of success with conservative treatment, in patients with imaging evidence of progressive destruction of the spinal column or with progressive neurological deficits, conservative treatment should be discontinued, and surgical treatment should be performed. Similarly, when clinical improvement is not achieved after an initial period of conservative treatment for approximately six weeks, surgical treatment should be considered as well [69,70]. It is desirable to begin antibiotics therapy after isolation of the responsible pathogen [55], except if a patient's condition is deteriorating [71].

There is a wide range of antibiotics for spinal infections. In critically ill patients or when cultures are negative, a dual-agent empirical therapy including a third-generation cephalosporin or fluoroquinolones, plus clindamycin or vancomycin is recommended. Until isolation of the causative pathogen, empirical treatment should include clindamycin/vancomycin/flucloxacillin + cefepime/ ciprofloxacin/ceftriaxone to cover a wide spectrum of potential pathogens (Table 2). Subsequently, antibiotics therapy should be modified based on the results of cultures. An anti-staphylococcal penicillin or a first-generation cephalosporin is the recommended antibiotic regimen when a methicillin-sensitive Staphylococcus is isolated. Otherwise, when a methicillin-resistant microorganism is identified, which is common with Staphylococcus aureus pathogens, a glucopeptide antibiotic such as vancomycin or teicoplanin is indicated. Alternative agents include quinupristin-dalfopristin or linezolid. When Streptococcus spp. are identified, penicillin G is the recommended antibiotic agent [72]. In cases of Gram-negative microorganisms, a second- or third-generation cephalosporin, or a quinolone can be administered, whereas for anaerobic pathogens metronidazole or clindamycin are recommended.

Table 2. Antibiotics for initial and empirical treatment.

\begin{tabular}{cc}
\hline Agents & Bacterial Susceptibility \\
\hline Clindamycin, Flucloxacillin, Vancomycin, Teicoplanin & Staphylococcus, Streptococcus, MRSA \\
\hline Ciprofloxacin, Cefepime & Gram-negative bacteria \\
\hline $\begin{array}{c}\text { Chloramphenicol, Amoxicillin+Clavulanic acid, } \\
\text { Meropenem/Imepenem, }\end{array}$ & Anaerobic bacteria \\
\hline
\end{tabular}

The recommended regimen for spinal tuberculosis includes multiple agents given that the risk of antibiotic resistance is significantly high [73]. The recommended four-agents regimen includes isoniazid, rifampicin, ethambutol, and pyrazinamide. For spinal infections caused by Brucella, a dual agent antibiotic treatment with doxycycline and streptomycin (or gentamicin) is recommended. In rare cases of fungal infections, a long-term treatment with azole or amphotericin B should be administered [72]. Despite the general recommendations regarding the antibiotic agents, it should be noted that in each case the antibiotic regimen must be individualized based on the cultures and susceptibilities of the isolated pathogens to certain antibiotic agents.

The optimal duration of antimicrobial therapy for spinal infections is highly debatable [45]. There is a wide variety of recommendations [1,44], with most authors recommending a period of four to six weeks [44], while others recommending a longer period of up to three months [68,74]. In a recent randomized controlled trial enrolling 359 patients with pyogenic spondylitis, the authors concluded that a six-week antibiotic treatment was similarly successful and safe to a 12-week treatment [75]. In that study, 176 patients were allocated to the six-week antibiotic group, while 175 patients were allocated to the 12-week group. In both groups, approximately $90 \%$ of patients were successfully treated and clinically cured, while the rate of adverse events was similar; death incidence was $8 \%$ for the six-week group vs. $7 \%$ for the 12 -week group, drug intolerance was $7 \%$ vs. 5\%, and neurological complications occurred in $4 \%$ vs. $2 \%$ of the patients [75].

Antibiotics therapy can be discontinued when clinical improvement with resolution of symptoms is evident, and the inflammatory markers are normalized [3]. However, in spinal infections caused by Brucella or Mycobacterium tuberculosis, a longer antibiotic treatment is required. Although the exact optimal duration is unclear, patients with Brucella infections should be administered antibiotics for three to six months [76], and patients with spinal tuberculosis should be administered even longer; 
usually 9 to 12 months of antibiotic treatment is recommended for eradication of the mycobacterial infection and prevention of recurrence using a four-agents regimen for the first two months, limited to two agents for the rest of this period $[71,77,78]$. There are no specific guidelines regarding the duration of treatment for fungal infections, and a more individualized approach is recommended in these cases taking into consideration the side effects of antifungal antibiotics and the clinical response to treatment [79]. The duration of treatment is also recommended to be longer in cases of undrained abscesses or in patients with infected spinal implants (Figure 3) [74]. Similar to adults, there are no specific guidelines about the duration of therapy in children. A common protocol for children includes intravenous antibiotics for one to three weeks until clinical and laboratory improvement is evident, followed by oral antibiotic for another one to three weeks [1].
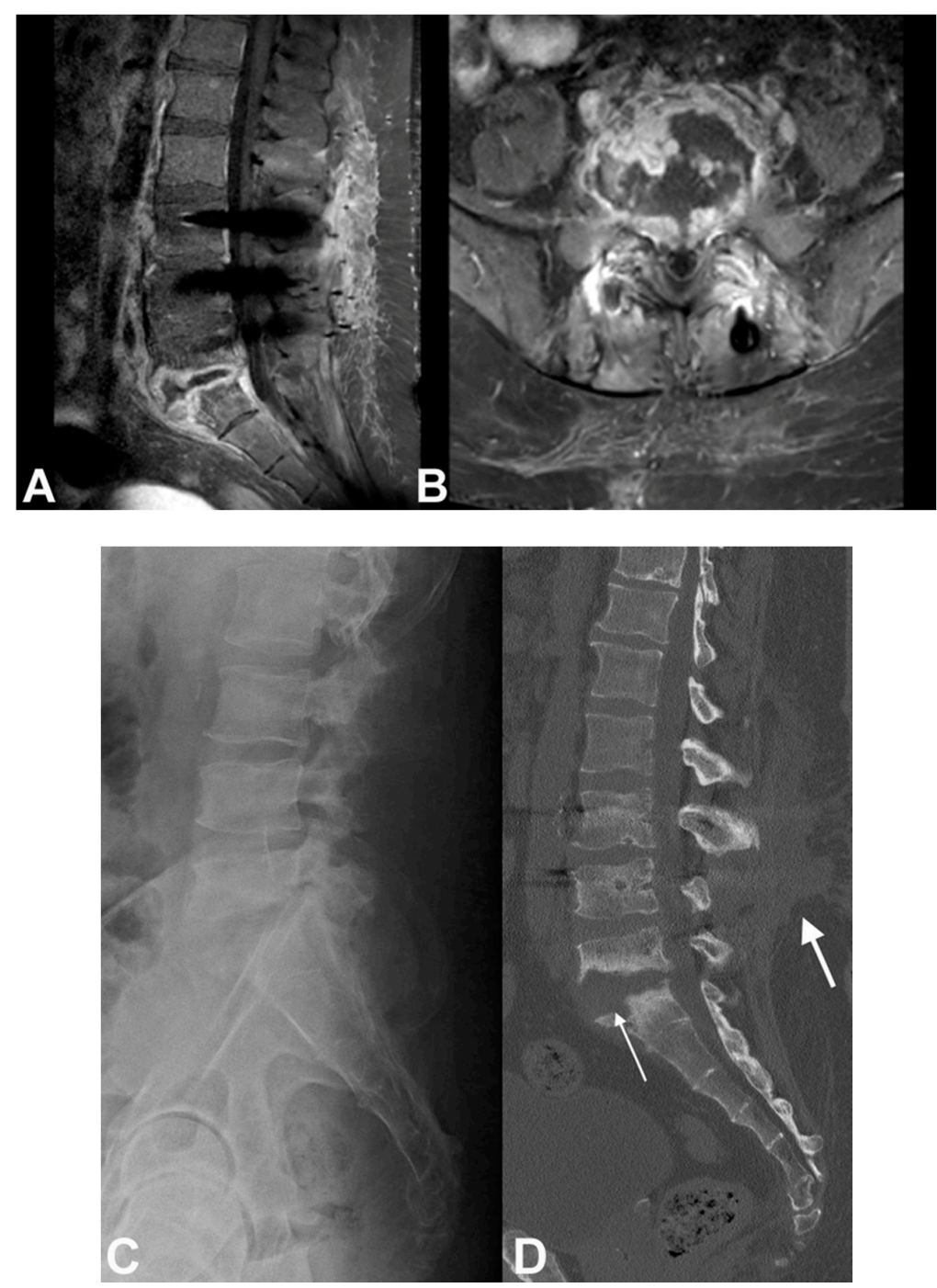

Figure 3. A 42-year-old woman with insulin dependent diabetes mellitus and obesity, and MRSA infection 1 year after L3-L5 laminectomy and spinal instrumentation. (A) Sagittal and (B) axial MR imaging show abscess formation and implants loosening at the site of instrumentation. She was treated with surgical debridement and implants removal followed by a 6-month antibiotics regimen; (C) Lateral radiograph and (D) sagittal CT scan of the lumbar spine show erosion of L5-S1 vertebrae (thin arrow) and extensive scar tissue formation (thick arrow).

Intravenous administration of antibiotics is recommended for the first two to four weeks [69], although there are contradicting data regarding the efficacy of switching to oral antibiotics in less than four weeks $[80,81]$. Oral antibiotics with high bioavailability such as fluoroquinolones allow a safer switch from intravenous treatment, while other agents with lower bioavailability such as 
beta-lactam antibiotics are not recommended to be used as sole oral antibiotics following intravenous treatment [74]. Recent studies have suggested that an early switch to oral antibiotics has similar results to long term intravenous antibiotics [82,83]. A large multicenter randomized study (OVIVA study) compared six-week intravenous antibiotics to six-week oral antibiotics for the treatment of osteomyelitis, including patients with spondylodiscitis. The primary end point in this study was definite treatment failure at one year. The authors found that there was non-inferiority with oral treatment [82]. Another retrospective study including patients with vertebral osteomyelitis treated surgically as compared with less than or equal to three weeks intravenous postoperative antibiotic course (followed by four weeks oral therapy) to a longer (greater than three weeks) intravenous antibiotic postoperative treatment and reported similar results in low risk patients; however, in patients with paraspinal abscess formation or positive blood cultures, short term therapy resulted in higher rate of recurrence [83].

It has been proposed that a 50\% weekly decrease in CRP levels indicates satisfactory clinical improvement [16]. In contrast, if fever and pain do not resolve after a four-week course of antibiotics, and CRP levels remain persistently high (>30 mg/l) failure of the conservative treatment is the most likely scenario and surgical treatment should be considered [74].

\section{Surgical Management}

Indications for surgery include failure of conservative treatment with no resolution of symptoms, septic status, spinal instability, spinal canal abscesses (Figure 4), paravertebral abscess $>2.5 \mathrm{~cm}$, and spinal cord or nerve root compression with progressive neurological deficits (Figure 5, Table 3) [45]. Spinal deformity such as kyphosis or scoliosis can be the end result of a spinal infection that in most cases need also to be addressed surgically [84]. Although in most cases surgical treatment is not needed, almost $50 \%$ of patients with spinal infection will undergo some sort of surgery [58].

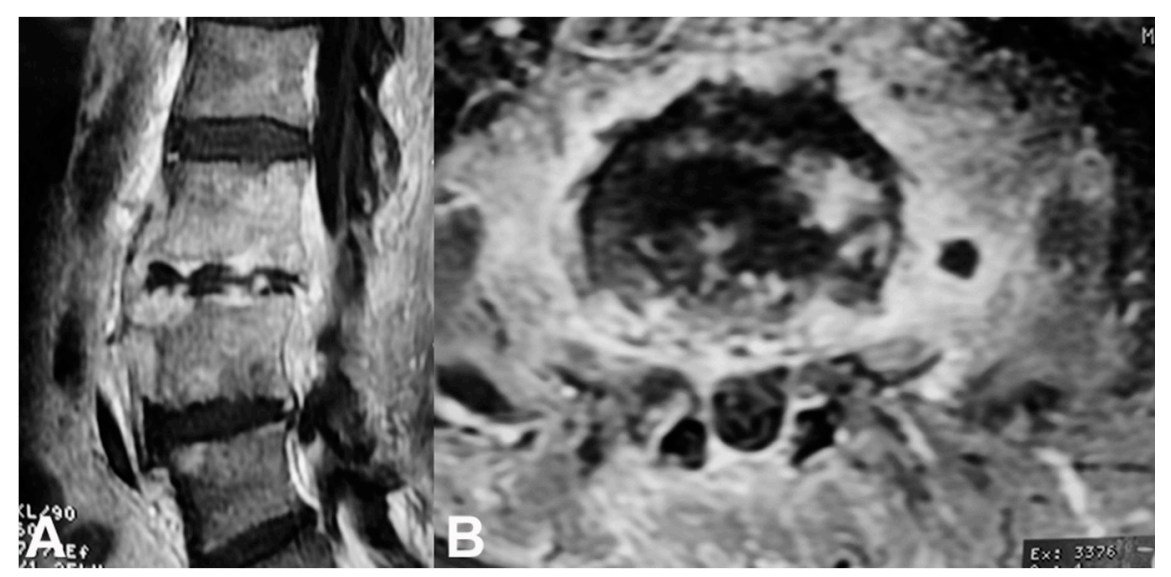

Figure 4. A 62-year-old man with L3-L4 MRSA spondylitis a couple of weeks after an infected olecranon bursitis. (A) Sagittal and (B) axial MR imaging show extensive destruction of the L3 and L4 vertebrae and abscess formation extending to the spinal canal. He was treated with surgical decompression and abscess drainage followed by a 6-month antibiotics regimen.

Usually, adequate surgical debridement and decompression is feasible only through an anterior approach, since in most cases the vertebral bodies and disks are affected. However, a posterior approach is required in cases of spinal canal abscess. In many cases, surgical debridement results in spinal instability, therefore, an additional stabilization procedure with bone grafting (either autograft or allograft) or spinal instrumentation is required. Moreover, anterior fusion only is not adequate in some cases, and a combined anterior-posterior approach with supplementary posterior stabilization can be required, especially in multi-segmental involvement [84]. Although large strut autografts are ideal for fusion due to their high rate of consolidation, they are associated with donor site morbidity. 
Therefore, instrumentation such as with titanium cages, as well as transpendicular screws and rods are commonly used. However, due to the risk of bacterial colonization of the implants, the issue of instrumentation in an infected environment is still debatable [84-86]. Staphylococcus can colonize hardware creating thick biofilm. It has been shown that there is limited biofilm formation on titanium due to a lack of porosity, therefore, it is a preferred material in such cases, and titanium cages have shown favorable results [60]. Prerequisites for spinal instrumentation at the time of debridement include thorough debridement and concomitant antibiotic therapy. Authors of a recent study reported $0 \%$ rate of recurrence in patients with spinal infections treated with fusion and instrumentation at the time of the debridement [85]. However, this was a small case series of nine patients, while patients received a long-term postoperative antibiotic course, up to 12 months. Another study reported a higher re-operation rate after decompression only vs. decompression and stabilization with spinal instrumentation [86].
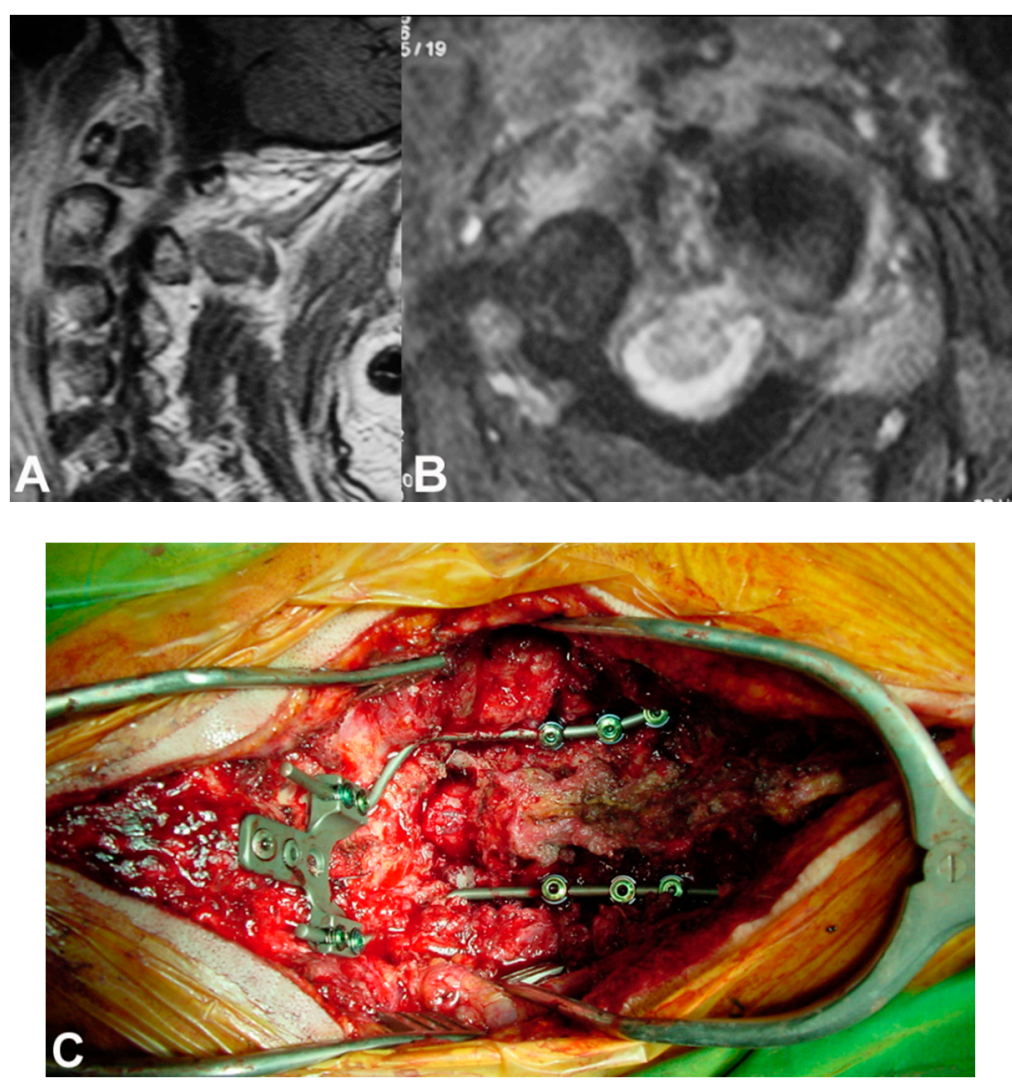

Figure 5. A 70-year-old man with a C1-C2 MRSA spondylitis and epidural abscess formation. (A) Sagittal and (B) axial MR imaging show erosion of the C1-C2, destruction of the odontoid process and abscess epidural formation. Because of progressive neurological deficits (tetraplegia) he was treated with (C) antero-posterior decrompression and craniocervical fusion followed by a 6-month antibiotics regimen.

Table 3. Indications for surgical treatment.

\begin{tabular}{c}
\hline Indications \\
\hline Failure of conservative treatment after 6-8 weeks \\
\hline Sepsis \\
\hline Progressive neurological dysfunction \\
\hline Spinal instability \\
\hline Epidural abscess
\end{tabular}


Patients with postoperative spinal infections and infected implants often require irrigation and debridement with implant removal [58]. Treatment management differs based on the chronicity of the postoperative infection. In patients with early infections (less than three months) with present spinal instrumentation, removal of the instrumentation is not recommended in order to avoid spinal destabilization in an infected bed [87,88]. Although loose bone grafts should be debrided during surgery, stable grafts that are adherent to native bone should be left in place.

Late postoperative infections are usually recommended to be treated with implant removal. First, given that solid fusion has been achieved, complete debridement is not feasible because areas such as spinal anchorage points or the region directly under the rods are relatively inaccessible without removing the instrumentation. Moreover, late postoperative infections are caused by microorganisms that usually form biofilms, such as coagulase-negative Staphylococci or Cutibacterium acnes. Di Silvestre et al. found that retention of the instrumentation during debridement of delayed spinal infections can result in $50 \%$ probability of persistent infection [89]. However, it is not always easy to assess whether osseous fusion has occurred, therefore, the benefit of eradicating the biofilm should be weighed against the risk of destabilizing the spine by removing fixation. Moreover, in chronic cases with long fusions, there is the risk of fracturing the fusion mass or lose alignment during implant removal. If osseous fusion has not achieved, bone grafts (autograft or allograft) can be used for bony fusion, without an increase in postoperative infection rate [89]. A treatment algorithm for spinal infection is presented in Figure 6.

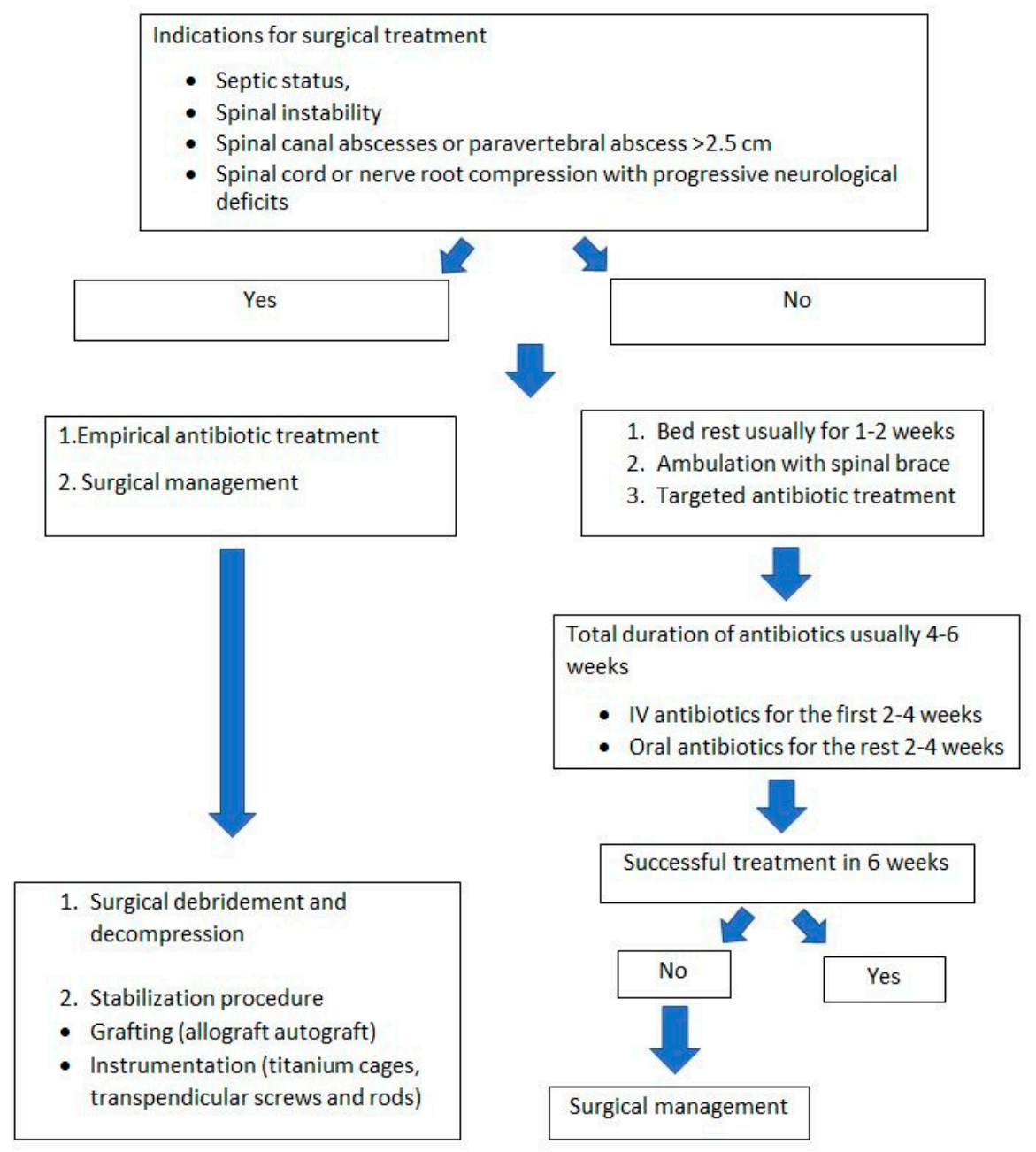

Figure 6. Treatment algorithm for spinal infections. 


\section{Conclusions}

The diagnostic approach of patients with spinal infections should include blood workup, blood or CT-guided needle cultures and histology, and imaging evaluation with radiographs and MR imaging. In addition to confirmation of the infection, the diagnostic algorithm should always aim to identify the source of the infection, and to establish a microbiological diagnosis. Provided that patients are neurologically intact and with no severe signs of infections, many authors propose withholding antibiotics, if empirically administered previously, in order to optimize culture sensitivity. However, when patients present with sepsis, empiric antibiotics should start immediately and not be withheld for cultures.

Most patients with spinal infections diagnosed in early stages can be successfully managed conservatively with antibiotics, bed rest, and spinal braces; a commonly used empirical antibiotics regimen includes vancomycin and a third-generation cephalosporin (such as cefepime) or a fluoroquinolone to cover MRSA and Gram-negative organisms, but other antibiotic regimens with similar coverage can be used as well. In cases of gross or pending instability, progressive neurological deficits, failure of conservative treatment, spinal abscess formation, severe symptoms indicating sepsis, and failure of previous conservative treatment surgical treatment is required.

Close monitoring of the patients with spinal infection with serial neurological examinations and imaging studies is necessary. Although the main goals of management and the overall treatment protocols have not changed over time, antibiotic therapy and techniques for spinal stabilization have significantly evolved and improved. Titanium implants currently are the optimal hardware for stabilization following debridement, due their favorable properties resulting in less biofilm formation.

Funding: This research received no external funding.

Conflicts of Interest: None. No benefits have been or will be received from a commercial party related directed or indirectly to the subject matter of this article.

\section{References}

1. Babic, M.; Simpfendorfer, C. Infections of the Spine. Infect. Dis. Clin. N. Am. 2017, 31, 279-297. [CrossRef] [PubMed]

2. Hadjipavlou, A.G.; Mader, J.T.; Necessary, J.T.; Muffoletto, A.J. Hematogenous pyogenic spinal infections and their surgical management. Spine (Phila Pa 1976) 2000, 25, 1668-1679. [CrossRef] [PubMed]

3. Aljawadi, A.; Jahangir, N.; Jelani, A.; Ferguson, Z.; Niazi, N.; Arnal, F.; Pillai, A. Management of Pyogenic Spinal Infection, review of literature. J. Orthop. 2019, 16, 508-512. [CrossRef] [PubMed]

4. Grammatico, L.; Baron, S.; Rusch, E.; Lepage, B.; Surer, N.; Desenclos, J.C.; Besnier, J.M. Epidemiology of vertebral osteomyelitis (VO) in France: Analysis of hospital-discharge data 2002-2003. Epidemiol. Infect. 2008, 136, 653-660. [CrossRef] [PubMed]

5. Beronius, M.; Bergman, B.; Andersson, R. Vertebral osteomyelitis in Goteborg, Sweden: A retrospective study of patients during 1990-1995. Scand. J. Infect. Dis. 2001, 33, 527-532. [PubMed]

6. Solera, J.; Lozano, E.; Martinez-Alfaro, E.; Espinosa, A.; Castillejos, M.L.; Abad, L. Spondylitis: Review of 35 cases and literature survey. Clin. Infect. Dis. 1999, 29, 1440-1449. [CrossRef] [PubMed]

7. Gupta, A.; Kowalski, T.J.; Osmon, D.R.; Enzler, M.; Steckelberg, J.M.; Huddleston, P.M.; Nassr, A.; Mandrekar, J.M.; Berbari, E.F. Long-term outcome of pyogenic vertebral osteomyelitis: A cohort study of 260 patients. Open Forum Infect. Dis. 2014, 1, ofu107. [CrossRef]

8. Legout, L.; Assal, M.; Rohner, P.; Lew, D.; Bernard, L.; Hoffmeyer, P. Successful treatment of Candida parapsilosis (fluconazole-resistant) osteomyelitis with caspofungin in a HIV patient. Scand. J. Infect. Dis. 2006, 38, 728-730. [CrossRef]

9. Sethna, N.F.; Clendenin, D.; Athiraman, U.; Solodiuk, J.; Rodriguez, D.P.; Zurakowski, D. Incidence of epidural catheter-associated infections after continuous epidural analgesia in children. Anesthesiology 2010, 113, 224-232. [CrossRef] [PubMed] 
10. Pigrau, C.; Rodriguez-Pardo, D.; Fernandez-Hidalgo, N.; Moretó, L.; Pellise, F.; Larrosa, M.N.; Puig, M.; Almirante, B. Health care associated hematogenous pyogenic vertebral osteomyelitis: A severe and potentially preventable infectious disease. Medicine (Baltim.) 2015, 94, e365. [CrossRef]

11. Larson, D.L.; Hudak, K.A.; Waring, W.P.; Orr, M.R.; Simonelic, K. Protocol management of late-stage pressure ulcers: A 5-year retrospective study of 101 consecutive patients with 179 ulcers. Plast. Reconstr. Surg. 2012, 129, 897-904. [CrossRef] [PubMed]

12. Türk, E.E.; Tsokos, M.; Delling, G. Autopsy-based assessment of extent and type of osteomyelitis in advanced-grade sacral decubitus ulcers: A histopathologic study. Arch. Pathol. Lab. Med. 2003, 127, 1599-1602. [PubMed]

13. Park, K.H.; Cho, O.H.; Jung, M.; Suk, K.S.; Lee, J.H.; Park, J.S.; Ryu, K.N.; Kim, S.H.; Lee, S.O.; Choi, S.H.; et al. Clinical characteristics and outcomes of hematogenous vertebral osteomyelitis caused by gram-negative bacteria. J. Infect. 2014, 69, 42-50. [CrossRef]

14. Michel-Batot, C.; Dintinger, H.; Blum, A.; Olivier, P.; Laborde, F.; Bettembourg-Brault, I.; Pourel, J.; Loeuille, D.; Chary-Valckenaere, I. A particular form of septic arthritis: Septic arthritis of facet joint. Jt. Bone Spine 2008, 75, 78-83. [CrossRef] [PubMed]

15. Tsantes, A.; Papadopoulos, D.V.; Lytras, T.; Tsantes, A.E.; Mavrogenis, A.F.; Koulouvaris, P.; Gelalis, I.D.; Ploumis, A.; Korompilias, A.V.; Benzakour, T.; et al. Association of malnutrition with surgical site infection following spinal surgery: Systematic review and meta-analysis. J. Hosp. Infect. 2020, 104, 111-119. [CrossRef]

16. Gouliouris, T.; Aliyu, S.H.; Brown, N.M. Spondylodiscitis: Update on diagnosis and management. J. Antimicrob. Chemother. 2010, 65, iii11-iii24. [CrossRef]

17. Sai Kiran, N.A.; Vaishya, S.; Kale, S.S.; Sharma, B.S.; Mahapatra, A.K. Surgical results in patients with tuberculosis of the spine and severe lower-extremity motor study of 48 patients. J. Neurosurg. Spine 2007, 6, 320-326. [CrossRef]

18. Patzakis, M.J.; Rao, S.; Wilkins, J.; Moore, T.M.; Harvey, P.J. Analysis of 61 cases of vertebral osteomyelitis. Clin. Orthop. Relat. Res. 1991, 264, 178-183. [CrossRef]

19. Weinstein, M.A.; Eismont, F.J. Infections of the spine in patients with human immunodeficiency virus. J. Bone Jt. Surg. Am. 2005, 87, 604-609. [CrossRef]

20. Rezai, A.R.; Woo, H.H.; Errico, T.J.; Cooper, P.R. Contemporary management of spinal osteomyelitis. Neurosurgery 1999, 44, 1018-1025. [CrossRef]

21. Dufour, V.; Feydy, A.; Rillardon, L.; Redondo, A.; Le Page, L.; Bert, F.; Belmatoug, N.; Fantin, B. Comparative study of postoperative and spontaneous pyogenic spondylodiscitis. Semin. Arthritis Rheum. 2005, 34, 766-771. [CrossRef] [PubMed]

22. Perlroth, J.; Kuo, M.; Tan, J.; Bayer, A.S.; Miller, L.G. Adjunctive use of rifampin for the treatment of Staphylococcus aureus infections: A systematic review of the literature. Arch. Intern. Med. 2008, 168, 805-819. [CrossRef] [PubMed]

23. Vartzelis, G.; Theodoridou, M.; Daikos, G.L.; Dellagrammaticas, H.; Syriopoulou, V.P. Brain abscesses complicating Staphylococcus aureus sepsis in a premature infant. Infection 2005, 33, 36-38. [CrossRef] [PubMed]

24. Baker, A.S.; Ojemann, R.G.; Swartz, M.N.; Richardson, E.P. Spinal Epidural Abscess. N. Engl. J. Med. 1975, 293, 463-468. [CrossRef]

25. Graybill, J.R.; Sobel, J.; Saag, M.; Van Der Horst, C.; Powderly, W.; Cloud, G.; Riser, L.; Hamill, R.; Dismukes, W. Diagnosis and management of increased intracranial pressure in patients with aids and cryptococcal meningitis. The NIAID Mycoses Study Group and AIDS Cooperative Treatment Groups. Clin. Infect. Dis. 2000, 30, 47-54. [CrossRef]

26. Hodgson, A.R. Report on the findings and results in 300 cases of Pott's disease treated by anterior fusion of the spine. J. W. Pac. Orthop. Assoc. 1964, 1, 3.

27. Berbari, E.F.; Kanj, S.S.; Kowalski, T.J.; Darouiche, R.O.; Widmer, A.F.; Schmitt, S.K.; Hendershot, E.F.; Holtom, P.D.; Huddleston, P.M., 3rd; Petermann, G.W.; et al. Infectious Diseases Society of America. 2015 Infectious Diseases Society of America (IDSA) clinical practice guidelines for the diagnosis and treatment of native vertebral osteomyelitis in adults. Clin. Infect. Dis. 2015, 61, e26-e46.

28. Erly, W.K.; Carmody, R.F.; Seeger, J.F.; Lund, P.J. Magnetic resonance imaging of coccidioidal spondylitis. Int. J. Neuroradiol. 1997, 3, 385-392. 
29. Brown-Elliott, B.A.; Brown, J.M.; Conville, P.S.; Wallace, R.J. Clinical and laboratory features of the Nocardia spp. based on current molecular taxonomy. Clin. Microbiol. Rev. 2006, 19, 259-282. [CrossRef]

30. Jeong, S.J.; Choi, S.W.; Youm, J.Y.; Kim, H.W.; Ha, H.G.; Yi, J.S. Microbiology and epidemiology of infectious spinal disease. J. Korean Neurosurg. Soc. 2014, 56, 21-27. [CrossRef]

31. Pappas, P.G.; Kauffman, C.A.; Andes, D.R.; Clancy, C.J.; Marr, K.A.; Ostrosky-Zeichner, L.; Reboli, A.C.; Schuster, M.G.; Vazquez, J.A.; Walsh, T.J.; et al. Clinical practice guideline for the management of candidiasis: 2016 update by the Infectious Diseases Society of America. Clin. Infect. Dis. 2016, 62, e1-e50. [CrossRef] [PubMed]

32. Kapeller, P.; Fazekas, F.; Krametter, D.; Koch, M.; Roob, G.; Schmidt, R.; Offenbacher, H. Pyogenic infectious spondylitis: Clinical, laboratory and MRI features. Eur. Neurol. 1997, 38, 94-98. [CrossRef] [PubMed]

33. Davis, D.P.; Wold, R.M.; Patel, R.J.; Tran, A.J.; Tokhi, R.N.; Chan, T.C.; Vilke, G.M. The clinical presentation and impact of diagnostic delays on emergency department patients with spinal epidural abscess. J. Emerg. Med. 2004, 26, 285-291. [CrossRef] [PubMed]

34. Tuchman, A.; Pham, M.; Hsieh, P.C. The indications and timing for operative management of spinal epidural abscess: Literature review and treatment algorithm. Neurosurg. Focus 2014, 37, E8. [CrossRef]

35. Darbyshire, J.; Fox, W.; Griffiths, M.D.L.; Tall, M.R. Controlled trial of short-course regimens of chemotherapy in the ambulatory treatment of spinal tuberculosis. Results at three years of a study in Korea. Twelfth report of the Medical Research Council Working Party on Tuberculosis of the Spine. J. Bone Jt. Surg. Br. 1993, 75, 240-248.

36. Guler, N.; Palanduz, A.; Ones, U.; Oztürk, A.; Somer, A.; Salman, N.; Yalçin, I. Progressive vertebral blastomycosis mimicking tuberculosis. Pediatr. Infect. Dis. J. 1995, 14, 816-818. [CrossRef]

37. Speed, B.; Dunt, D. Clinical and host differences between infections with the two varieties of Cryptococcus neoformans. Clin. Infect. Dis. 1995, 21, 28-34. [CrossRef]

38. Gamaletsou, M.N.; Rammaert, B.; Bueno, M.A.; Sipsas, N.V.; Moriyama, B.; Kontoyiannis, D.P.; Roilides, E.; Zeller, V.; Taj-Aldeen, S.J.; Henry, M.; et al. Aspergillus osteomyelitis: Epidemiology, clinical manifestations, management, and outcome. J. Infect. 2014, 68, 478-493. [CrossRef]

39. Mavrogenis, A.F.; Triantafyllopoulos, G.K.; Kokkinis, K.; Stefos, A.; Sipsas, N.V.; Pneumaticos, S.G. Continuous L3 spondylitis caused by an infected endovascular aortic graft. Surg. Infect. (Larchmt.) 2014, 15, 861-862. [CrossRef]

40. Megaloikonomos, P.; Antoniadou, T.; Dimopoulos, L.; Liontos, M.; Igoumenou, V.; Panagopoulos, G.N.; Giannitsioti, E.; Lazaris, A.; Mavrogenis, A.F. Spondylitis transmitted from infected aortic grafts: A review. J. Bone Jt. Infect. 2017, 2, 96-103. [CrossRef]

41. Batson, O.V. The vertebral system of veins as a means for cancer dissemination. Prog. Clin. Cancer 1967, 3, 1-18. [PubMed]

42. Dunphy, L.; Iyer, S.; Brown, C. Rare cause of back pain: Staphylococcus aureus vertebral osteomyelitis complicated by recurrent epidural abscess and severe sepsis. BMJ Case Rep. 2016, 2016, bcr2016217111. [CrossRef] [PubMed]

43. Choi, S.; Jung, K.H.; Son, H.J.; Lee, S.H.; Hong, J.M.; Kim, M.C.; Kim, M.J.; Chong, Y.P.; Sung, H.; Lee, S.O.; et al. Diagnostic usefulness of the QuantiFERON-TB gold in-tube test (QFT-GIT) for tuberculous vertebral osteomyelitis. Infect. Dis. (Lond.) 2018, 50, 346-351. [CrossRef] [PubMed]

44. Lew, D.P.; Waldvogel, F.A. Osteomyelitis. Lancet 2004, 364, 369-379. [CrossRef]

45. Saeed, K.; Esposito, S.; Ascione, T. Hot topics on vertebral osteomyelitis from the International Society of Antimicrobial Chemotherapy. Int. J. Antimicrob. Agents 2019, 54, 125-133. [CrossRef]

46. Lazzeri, E.; Pauwels, E.K.; Erba, P.A. Clinical feasibility of two-step streptavidin/ 111In-biotin scintigraphy in patients with suspected vertebral osteomyelitis. Eur. J. Nucl. Med. Mol. Imaging 2004, 31, 1505-1511. [CrossRef]

47. Lupetti, A.; Welling, M.M.; Mazzi, U.; Nibbering, P.H.; Pauwels, E.K. Technetium-99m labelled fluconazole and antimicrobial peptides for imaging of Candida albicans and Aspergillus fumigatus infections. Eur. J. Nucl. Med. Mol. Imaging 2002, 29, 674-679. [CrossRef]

48. Pupaibool, J.; Vasoo, S.; Erwin, P.; Murad, M.; Berbari, E. The utility of image-guided percutaneous needle aspiration biopsy for the diagnosis of spontaneous vertebral osteomyelitis: A systematic review and meta-analysis. Spine J. 2015, 15, 122-131. [CrossRef] 
49. Foreman, S.C.; Schwaiger, B.J.; Gempt, J.; Jungmann, P.M.; Kehl, V.; Delbridge, C.; Wantia, N.; Zimmer, C.; Kirschke, J.S. MR and CT Imaging to optimize CT-guided biopsies in suspected spondylodiscitis. World Neurosurg. 2017, 99, 726-734. [CrossRef]

50. Spira, D.; Germann, T.; Lehner, B.; Hemmer, S.; Akbar, M.; Jesser, J.; Weber, M.A.; Rehnitz, C. CT-guided biopsy in suspected spondylodiscitis-The association of paravertebral inflammation with microbial pathogen detection. PLoS ONE 2016, 11, e0146399. [CrossRef]

51. Kim, C.J.; Kang, S.J.; Choe, P.G.; Park, W.B.; Jang, H.C.; Jung, S.I.; Song, K.H.; Kim, E.S.; Kim, H.B.; Oh, M.D.; et al. Which tissues are best for microbiological diagnosis in patients with pyogenic vertebral osteomyelitis undergoing needle biopsy? Clin. Microbiol. Infect. 2015, 21, 931-935. [CrossRef] [PubMed]

52. Lecouvet, F.; Irenge, L.; Vandercam, B.; Nzeusseu, A.; Hamels, S.; Gala, J.L. The etiologic diagnosis of infectious discitis is improved by amplification-based DNA analysis. Arthritis Rheum. 2004, 50, 2985-2994. [CrossRef] [PubMed]

53. Wang, G.; Dong, W.; Lan, T.; Fan, J.; Tang, K.; Li, Y.; Yan, G.; Jiang, G.; Ma, Y.; Shang, Y.; et al. Diagnostic accuracy evaluation of the conventional and molecular tests for Spinal Tuberculosis in a cohort, head-to-head study. Emerg. Microbes Infect. 2018, 7, 109. [CrossRef] [PubMed]

54. Saravolatz, L.D.; Labalo, V.; Fishbain, J.; Szpunar, S.; Johnson, L.B. Lack of effect of antibiotics on biopsy culture results in vertebral osteomyelitis. Diagn. Microbiol. Infect. Dis. 2018, 91, 273-274. [CrossRef]

55. Marschall, J.; Bhavan, K.P.; Olsen, M.A.; Fraser, V.J.; Wright, N.M.; Warren, D.K. The impact of prebiopsy antibiotics on pathogen recovery in hematogenous vertebral osteomyelitis. Clin. Infect. Dis. 2011, 52, 867-872. [CrossRef]

56. Gras, G.; Buzele, R.; Parienti, J.J.; Debiais, F.; Dinh, A.; Dupon, M.; Roblot, F.; Mulleman, D.; Marcelli, C.; Michon, J.; et al. Microbiological diagnosis of vertebral osteomyelitis: Relevance of second percutaneous biopsy following initial negative biopsy and limited yield of post-biopsy blood cultures. Eur. J. Clin. Microbiol. Infect. Dis. 2014, 33, 371-375. [CrossRef]

57. Yee, D.K.; Samartzis, D.; Wong, Y.W.; Luk, K.D.; Cheung, K.M. Infective spondylitis in Southern Chinese: A descriptive and comparative study of ninety-one cases. Spine (Phila Pa 1976) 2010, 35, 635-641. [CrossRef]

58. Loibl, M.; Stoyanov, L.; Doenitz, C.; Brawanski, A.; Wiggermann, P.; Krutsch, W.; Nerlich, M.; Oszwald, M.; Neumann, C.; Salzberger, B.; et al. Outcome-related co-factors in 105 cases of vertebral osteomyelitis in a tertiary care hospital. Infection 2014, 42, 503-510. [CrossRef]

59. Legrand, E.; Flipo, R.M.; Guggenbuhl, P.; Masson, C.; Maillefert, J.F.; Soubrier, M.; Noël, E.; Saraux, A.; Di Fazano, C.S.; Sibilia, J.; et al. Management of nontuberculous infectious discitis. treatments used in 110 patients admitted to 12 teaching hospitals in France. J. Bone Spine 2001, 68, 504-509. [CrossRef]

60. Cebrián Parra, J.L.; Saez-Arenillas Martín, A.; Urda Martínez-Aedo, A.L.; Soler Ivañez, I.; Agreda, E.; Lopez-Duran Stern, L. Management of infectious discitis. Outcome in one hundred and eight patients in a university hospital. Int. Orthop. 2012, 36, 239-244. [CrossRef]

61. Cottle, L.; Riordan, T. Infectious spondylodiscitis. J. Infect. 2008, 56, 401-412. [CrossRef]

62. Broner, F.A.; Garland, D.E.; Zigler, J.E. Spinal infections in the immunocompromised host. Orthop. Clin. N. Am. 1996, 27, 37-46.

63. D'Agostino, C.; Scorzolini, L.; Massetti, A.P.; Carnevalini, M.; d'Ettorre, G.; Venditti, M.; Vullo, V.; Orsi, G.B. A seven-year prospective study on spondylodiscitis: Epidemiological and microbiological features. Infection 2010, 38, 102-107. [CrossRef]

64. Chuo, C.Y.; Fu, Y.C.; Lu, Y.M.; Chen, J.C.; Shen, W.J.; Yang, C.H.; Chen, C.Y. Spinal infection in intravenous drug abusers. J. Spinal Disord. Tech. 2007, 20, 324-328. [CrossRef]

65. Tyagi, R. Spinal infections in children: A review. J. Orthop. 2016, 13, 254-258. [CrossRef]

66. Ulu-Kilic, A.; Karakas, A.; Erdem, H. Update on treatment options for spinal brucellosis. Clin. Microbiol. Infect. 2014, 20, O75-O82. [CrossRef]

67. Charles, R.W.; Govender, S.; Naidoo, K.S. Echinococcal infection of the spine with neural involvement. Spine (Phila Pa 1976) 1988, 13, 47-49. [CrossRef]

68. Roblot, F.; Besnier, J.M.; Juhel, L.; Vidal, C.; Ragot, S.; Bastides, F.; Le Moal, G.; Godet, C.; Mulleman, D.; Azaïs, I.; et al. Optimal duration of antibiotic therapy in vertebral osteomyelitis. Semin. Arthritis Rheum. 2007, 36, 269-277. [CrossRef]

69. Zarghooni, K.; Röllinghoff, M.; Sobottke, R.; Eysel, P. Treatment of spondylodiscitis. Int. Orthop. 2012, 36, 405-411. [CrossRef] 
70. Sobottke, R.; Seifert, H.; Fätkenheuer, G.; Schmidt, M.; Goßmann, A.; Eysel, P. Current diagnosis and treatment of spondylodiscitis. Dtsch. Arztebl. Int. 2008, 105, 181-187. [CrossRef]

71. Tsiodras, S.; Falagas, M.E. Clinical assessment and medical treatment of spineinfections. Clin. Orthop. Relat. Res. 2006, 444, 38-50. [CrossRef] [PubMed]

72. Butler, J.S.; Shelly, M.J.; Timlin, M.; Powderly, W.G.; O’Byrne, J.M. Nontuberculous pyogenic spinal infection in adults: A 12-year experience from a tertiary referral center. Spine (Phila Pa 1976) 2006, 31, 2695-2700. [CrossRef] [PubMed]

73. Shi, T.; Zhang, Z.; Dai, F.; Zhou, Q.; He, Q.; Luo, F.; Hou, T.; Xu, J. Retrospective Study of 967 Patients With Spinal Tuberculosis. Orthopedics 2016, 39, e838-e843. [CrossRef]

74. Zimmerli, W. Clinical practice. Vertebral osteomyelitis. N. Engl. J. Med. 2010, 362, 1022-1029. [CrossRef]

75. Bernard, L.; Dinh, A.; Ghout, I.; Simo, D.; Zeller, V.; Issartel, B.; Le Moing, V.; Belmatoug, N.; Lerprit, P.; Bru, J.P.; et al. Duration of Treatment for Spondylodiscitis (DTS) study group. Antibiotic treatment for 6 weeks versus 12 weeks in patients with pyogenic vertebral osteomyelitis: An open-label, non-inferiority, randomised, controlled trial. Lancet 2015, 385, 875-882. [CrossRef]

76. Chelli Bouaziz, M.; Ladeb, M.F.; Chakroun, M.; Chaabane, S. Spinal brucellosis: A review. Skeletal Radiol. 2008, 37, 785-790. [CrossRef]

77. Lee, K.Y. Comparison of pyogenic spondylitis and tuberculous spondylitis. Asian Spine J. 2014, 8, $216-223$. [CrossRef]

78. Govender, S.; Parbhoo, A.H.; Kumar, K.P.; Annamalai, K. Anterior spinal decompression in HIV-positive patients with tuberculosis: A prospective study. J. Bone Jt. Surg. Br. 2001, 83, 864-867. [CrossRef]

79. Govender, S.; Kumar, K.P.S. Aspergillus spondylitis in immunocompetent patients. Int. Orthop. 2001, 25, 74-76. [CrossRef]

80. Sapico, F.L.; Montgomerie, J.Z. Vertebral osteomyelitis. Infect. Dis. Clin. N. Am. 1990, 4, 539-550.

81. Babouee Flury, B.; Elzi, L.; Kolbe, M.; Frei, R.; Weisser, M.; Schären, S.; Widmer, A.F.; Battegay, M. Is switching to an oral antibiotic regimen safe after 2 weeks of intravenous treatment for primary bacterial vertebral osteomyelitis? BMC Infect. Dis. 2014, 14, 226. [CrossRef]

82. Li, H.K.; Rombach, I.; Zambellas, R.; Walker, A.S.; McNally, M.A.; Atkins, B.L.; Lipsky, B.A.; Hughes, H.C.; Bose, D.; Kümin, M.; et al. OVIVA Trial Collaborators. Oral versus intravenous antibiotics for bone and joint infection. N. Engl. J. Med. 2019, 380, 425-436. [CrossRef]

83. Li, Y.D.; Wong, C.B.; Tsai, T.T.; Lai, P.L.; Niu, C.C.; Chen, L.H.; Fu, T.S. Appropriate duration of post-surgical intravenous antibiotic therapy for pyogenic spondylodiscitis. BMC Infect. Dis. 2018, 18, 468. [CrossRef]

84. Mavrogenis, A.F.; Igoumenou, V.; Tsiavos, K.; Megaloikonomos, P.; Panagopoulos, G.N.; Vottis, C.; Giannitsioti, E.; Papadopoulos, A.; Soultanis, K.C. When and how to operate on spondylodiscitis: A report of 13 patients. Eur. J. Orthop. Surg. Traumatol. 2016, 26, 31-40. [CrossRef] [PubMed]

85. Talia, A.; Wong, M.; Lau, H.; Kaye, A. Safety of instrumentation and fusion at the time of surgical debridement for spinal infection. J. Clin. Neurosci. 2015, 22, 1111-1116. [CrossRef] [PubMed]

86. Karadimas, E.J.; Bunger, C.; Lindblad, B.E.; Hansen, E.S.; Høy, K.; Helmig, P.; Kannerup, A.S.; Niedermann, B. Spondylodiscitis. A retrospective study of 163 patients. Acta Orthop. 2008, 79, 650-659. [CrossRef]

87. Hegde, V.; Meredith, D.S.; Kepler, C.K.; Huang, R.C. Management of postoperative spinal infections. World J. Orthop. 2012, 3, 182-189. [CrossRef]

88. Núñez-Pereira, S.; Pellisé, F.; Rodríguez-Pardo, D.; Pigrau, C.; Bagó, J.; Villanueva, C.; Cáceres, E. Implant survival after deep infection of an instrumented spinal fusion. Bone Jt. J. 2013, 95, 1121-1126. [CrossRef]

89. Di Silvestre, M.D.; Bakaloudis, G.; Lolli, F.; Giacomini, S. Latedeveloping infection following posterior fusion for adolescent idiopathic scoliosis. Eur. Spine J. 2011, 20, S121-S127. [CrossRef] [PubMed]

(C) 2020 by the authors. Licensee MDPI, Basel, Switzerland. This article is an open access article distributed under the terms and conditions of the Creative Commons Attribution (CC BY) license (http://creativecommons.org/licenses/by/4.0/). 